Article

\title{
The Influence of Interactive Learning Materials on Self-Regulated Learning and Learning Satisfaction of Primary School Teachers in Mongolia
}

\author{
Shengru $\mathrm{Li}^{1, *(\mathbb{D})}$, Shinobu Yamaguchi ${ }^{2}$ and Jun-ichi Takada ${ }^{3}$ \\ 1 Department of International Development Engineering, Graduate School of Science and Engineering, \\ Tokyo Institute of Technology, Tokyo 152-8550, Japan \\ 2 Global Scientific and Computing Center, Tokyo Institute of Technology, Tokyo 152-8550, Japan; \\ yamaguchi@gsic.titech.ac.jp \\ 3 Department of Transdisciplinary Science and Engineering, School of Environment and Society, \\ Tokyo Institute of Technology, Tokyo 152-8550, Japan; takada@ide.titech.ac.jp \\ * Correspondence: li.s.ae@m.titech.ac.jp; Tel.: +81-03-5734-3420
}

Received: 15 March 2018; Accepted: 4 April 2018; Published: 5 April 2018

\begin{abstract}
The purpose of this study was to investigate the effects of interactive learning materials on learners' self-regulated learning processes and learning satisfaction. A two-group experimental design was employed for 285 primary school teachers involved in teacher training. Teachers in the experimental group utilised interactive learning materials along with training videos and guidelines for their self-development at the school level. Teachers in the control group conducted self-development only with training videos and guidelines. The result was analysed using self-regulated learning theory explaining how one's self-regulation processes affect learning satisfaction. Five self-regulation processes were identified in this study: internal motivation, motivation for better assessment, planning and organizing skills, critical and positive thinking skills, and effort regulation. The analysis was conducted in two steps. First, $t$-test analysis was used to identify the significant differences between the experimental group and the control group. The analysis revealed: (1) teachers conducting self-development with interactive learning materials were highly motivated to achieve better teacher assessment, (2) teachers with interactive learning materials had higher learning satisfaction. Second, the study further investigated the effect of interactive materials on the relationship between self-regulation processes and learning satisfaction, using moderation analysis. The results showed that interactive materials significantly affect the relationship between motivation for better assessment and learning satisfaction, as well as the relationship between internal motivation and learning satisfaction. These results were complemented by qualitative analysis including interviews and focus group discussions with teachers.
\end{abstract}

Keywords: interactive learning environments; ICT in education; in-service teacher training; self-regulated learning; country-specific developments

\section{Introduction}

Quality education is considered an important element of sustainable development. In 2012, United Nations passed the resolution "the future we want" which reaffirmed that full access to quality education on all levels, especially for people in rural areas is an essential condition for achieving sustainable development [1]. In order to achieve quality education, the capacity of education systems should be improved through methods such as implementing enhanced teacher training, and promoting more effective use of information and communication technologies to enhance learning outcomes [1]. This resolution is reflected in the Sustainable Development Goal (SDG) 4 of the United 
Nations, specifically, Target 4.c. This target aims to increase the provision of qualified teachers, through international collaboration for teacher training in developing countries, especially least developed countries and small island developing states [2]. One of the important indicators to measure Target 4.c of SDG 4 is the proportion of primary school teachers who have received the in-service pedagogical training required for quality teaching. The United Nations Educational, Scientific, Cultural Organization (UNESCO) puts emphasis on diverse methods of teacher training using Information and Communication Technology (ICT) for reaching teachers in remote areas and promoting quality teaching [3]. Teacher development using ICT reflecting local conditions is vitally important in achieving sustainable development.

In Mongolia, teacher development using ICT has been an important focus in the development of a quality educational system. Since the 1990s, the Mongolian education system has experienced a major transition from a centrally planned system to a decentralised system. This has resulted in increased roles and responsibilities for local governments and schools. With such major changes, school managers and teachers in rural schools have faced difficulties. The specific issues include a lack of quality teacher training, limited budget, and gaps in education quality between rural and urban schools [4]. In order to address the need for change in public schools in Mongolia, the government has allocated funds through policy implementations, especially for rural schools. As a result of the basic infrastructure reaching every province of Mongolia, recent policies are focusing on the introduction of ICT into locally contextualised teacher training programmes for the quality improvement of rural education. For example, the Education Master Plan 2006 and ICT Vision 2021 in education emphasized the use of ICT for teacher development [5,6]. The Education Sector (2012-2016) formulated a policy to improve the continuous professional development of teachers through a national teacher training platform [7]. Further, the Education Policy Action Plan (2012-2016) formed a plan to renew teacher training programmes in accordance with the latest ICT development, as well as new education standards and curriculums [8]. More recently, in 2015 the Ministry of Education, Culture, Science and Sports (MECSS) of Mongolia established a web-portal for promoting the utilization of electronic and interactive learning content [9].

With policy incentives encouraging teachers' professional development, school-level training has become a popular strategy to raise educational standards in such a dispersed population. Decentralization of educational management gave the responsibilities of teachers' professional development to local governments. Local governments are active in implementing new approaches for teachers' professional development through integrating ICT [10]. In the past decade, digitised teacher training materials such as teacher training videos have been produced by local educational practitioners and interactive teacher training materials have also been implemented. These locally produced digital teacher training materials are intended for self-learning at the school level by individual teachers. These teacher training activities are in-line with the SDG 4, through introducing ICT for in-service teacher development in rural Mongolia.

Distance learning environments, as well as the computer-mediated interactive learning environment often require learners to self-direct their learning mainly due to the absence of instructors or peers to keep the learning on track. Therefore, distance and interactive learning environments that support self-regulated learning are likely to enhance learning and its results. Self-regulation touches upon learning motivation, learning behaviours, and cognition skills to achieve the learning goal [11]. It was developed and widely examined in traditional classroom learning environments but self-regulated learning has been recently applied in studying online learning, and computer-mediated learning [12-15].

This study aims to investigate how interactive learning materials can support self-regulated learning processes and learning satisfaction for primary school teachers' self-development in Mongolia. 


\section{Literature Review and Theoretical Framework}

Self-regulated learning theory developed by Pintrich [16] is an important theory supporting the theoretical framework of this study. This section reviews this theory in relation to the professional development of teachers. It also discusses how self-regulated learning is understood in the context of teacher training using interactive materials.

\subsection{Self-Regulated Learning (SRL) Theory}

Self-regulated learning theory explains the process of planning and cyclically adapting self-generated thoughts, feelings, and actions to influence one's learning outcome [17]. It is not a mental ability or an academic performance skill, but is concerned about learner's self-directive processes to transform their mental abilities into academic skills [18]. Learners who are self-regulated view learning as an activity for themselves and approach learning proactively. Self-regulation processes comprise motivation and learning strategies $[11,19]$. Motivation refers to various motivational beliefs such as goal orientation (purpose of doing a task) and self-efficacy (judgements of competence in doing a task) [11]. Learning strategies contain cognitive strategies, metacognitive strategies, and resource management strategies. Cognitive strategies refer to mental operations, procedures and processes that the learner engage in to acquire, integrate, organize, and retain new information [11]. Metacognitive strategies refer to specific processes by which the learner evaluates or monitor their own thinking and knowledge structures, such as setting goals and self-monitoring. Finally, resource management strategies refer to learners' behaviours regarding changing tasks and learning conditions. Therefore, self-regulated learning is concerned with how learners activate and sustain their motivation and learning strategies to attain the learning objectives [20].

As indicated by SDG 4, promoting life-long learning for improving the quality of education is an important factor in achieving sustainable development. Self-regulation is very important in the discussion of sustainable life-long learning because adults often face the need to constantly refine their skills [20]. This concept can be applied to in-service teacher training, where Fullan views professional development for teachers to be both ongoing and dynamic [21]. Multiple studies report that teachers are often called upon to restructure their professional practices, across community and institutional, formal and informal, and all levels of education [22,23]. On one hand, teachers are asked to revise practices to match shifts in societal structure, values, or resources, for example, to integrate emerging technologies into classrooms [24]. On the other hand, teachers are expected to realign practices in line with evolving learning theories, such as constructivist learning theory [25]. With this background, self-regulated learning is of importance to teachers since they are engaged in training activities that promote ongoing reflection on practices aligning new policies and learning theories [22]. Teachers are also expected to identify instructional principles with the learning theories [26], plan activities consistent with such principles (e.g., conducting student-centred lesson), carry out their plans in practice, monitor outcomes, and critically reflect on their efforts [27,28]. Therefore, self-regulated learning skills are critical for teachers' in-service development since these skills are relevant in their self-development processes.

The Mongolian education sector has experienced a series of reforms since the 1990s. Teachers are expected to adapt to the new policies, curriculum, and pedagogies, including student-centred teaching and learning and the use of ICT in educational activities [7,29]. School-based teacher training is taking place to facilitate these movements in policies and practices. Provided with learning opportunities at the local school level, it is vital for Mongolian primary school teachers to be motivated to learn and practice different pedagogies, reflect on their professional practices, discuss and collaborate with peers to solve issues, and create an environment of self-development [30]. Since self-regulated learning theory is focused on learning motivations and learning strategies such as reflecting the knowledge, creating a learning environment, and collaborating with peers, it can serve as a fundamental theory to understand teachers' motivation and learning strategies in teacher training. 
Self-regulated learning was originally developed in the context of student learning in the classroom, and thus studies mainly focused on the influence of SRL on learning outcomes measured by academic achievement $[12,14,15,31-33]$. Although academic achievement was the main concern during the early development of the theory, Zimmerman discussed the importance of affective outcomes such as learning satisfaction as a part of the self-reflection phase in the SRL model [18]. He asserts that self-satisfaction and positive affect regarding the learner's performance is one form of self-reaction in the self-reflection phase. Affective outcomes such as learning satisfaction and attitudes have been widely examined $[13,34,35]$.

Furthermore, Zimmerman's concept of adapting self-satisfaction as the affective outcome in self-reflective processes has clear resonance with Pintrich's discussion on goal orientations [11]. Pintrich laid out two goal orientations: (i) mastery orientation, and (ii) performance orientation. Mastery orientated goals are represented by attempts to improve or promote competence, knowledge, and skills where the evaluation standards are self-referential with a focus on progress and understanding [11]. In contrast, performance orientated goals are represented by attempts to outperform others using normative standards. Pintrich argued that both mastery orientated and performance orientated goals will influence affective learning outcomes such as self-satisfaction as part of the reaction and reflection phase of self-regulated learning [36]. For example, Artino showed that two learning motivation constructs in SRL, namely task value and self-efficacy, positively affected learning satisfaction in an online military training course [37].

In the Mongolian context, self-development utilising digital training materials on the local school level is popular among primary school teachers due to the dispersed distribution of the population [30]. Teachers are expected to self-evaluate their understanding of the teacher training materials, and reflect the knowledge learnt in their pedagogy. Within this context, it is hard to capture the progress that teachers make in their self-development by using academic performance indicators. Instead, affective learning outcomes such as self-satisfaction are suitable for understanding the learning outcomes of teachers' self-development.

\subsection{Interactive Learning Materials and Self-Regulated Learning}

\subsubsection{Types of Interaction in Interactive Learning Materials}

Moore introduced three types of interaction in the distance learning context: (i) learner-content interaction, (ii) learner-instructor interaction, and (iii) learner-learner interaction [38]. Learner-content interaction refers to the interaction between the learner and the content for the subject of study. Learner-content interaction is considered as the intellectual process in interacting with the learning content that changes learner's understanding, or cognitive structures in their mind. Learner-instructor interaction refers to the interaction between the learner and the expert who prepared the distance learning material, such as receiving support from the instructor. Learner-learner interaction refers to the interaction between one learner and other learners, either individually or in groups such as group discussion and feedback.

There are two different focuses in discussing learner-content interaction. The origin of computer-mediated distance learning goes back to the early 1980s and evolved over time. First, during the late 1980s and 1990s, functional interactivity research promoted discussion among educators. This interactivity can be classified in terms of input devices (e.g., keyboard, mouse, touch screen) or features provided (e.g., hypertext, multimedia) [39-41]. In these cases, interactivity is defined as an attribute of the medium, with less focus on the dynamic relationship between the learner and the interactive learning system. Therefore, functional interactivity has a clear focus on the system, not on the learner. The above approach is of limited use for research on the effectiveness of interactivity in multimedia learning because it does not sufficiently consider the learner's learning processes. It has been argued that an interactive learning environment has functional interactivity attributes, but such an environment alone is not sufficient $[42,43]$. Instead a learner must release the potential of functional 
interactivity by establishing a dynamic relationship [43]. Thus, starting in the 2000sdiscussion on cognitive interactivity emerged, which focuses on learners' use of learning strategies to mentally process the knowledge presented in the interactive learning system [43,44].

Recent literature advances the previous discussion on interactivity in computer-mediated learning systems. Domagk and co-workers argue that interactivity is not the function of the learning system alone, nor merely the cognitive activities of the learner, but rather, it should be viewed as a reciprocal activity between the learner and an interactive learning system [42]. Therefore, the learner is at the core in establishing a dynamic, meaningful relationship with the interactive learning environment to make effective learning occur.

In the context of the Mongolian education system, school-based training is popular due to the dispersed population. Distance learning programmes are helpful in overcoming limited resources in the local educational environment. With this background, interactive materials are serving as potential tools for promoting local primary school teachers' self-development. Therefore, in this study, it is important to focus on the learner-content interaction, and the cognitive interaction of the learner with the interactive learning environment in the distance learning context.

\subsubsection{Self-Regulated Learning and Interactive Learning Materials}

This section discusses how self-regulated learning can be used to understand the effectiveness of interactive materials. The learner's ability to conduct self-regulated learning is vital in achieving learning objectives particularly in an environment where regular guidance and support from the instructor are not available. Such learning environments are different from traditional learning and training settings where the activities are structured and monitored. Instead, learning motivation and self-management skills are important assets for learners to succeed in a distance learning context [45].

In developing quality learner-content interactive materials, several design principles are considered important. Keller and co-workers illustrated multiple design principles in the interactive learning environment that may promote learning motivation [46,47]. Interactive learning environments that includes relevant and applicable knowledge for the learner can promote intrinsic motivation and task value, for which the contents catch learner's interest. The learning tasks in the interactive learning environment that are of appropriate difficulty can help learners establish self-efficacy for learning, by letting learners experience success with their own effort. Interactive learning environments also have the potential to provide feedback that confirms the learning efforts of the learner. This feature makes it possible to elevate the learner's belief that their efforts that can lead to positive outcomes. Furthermore, Carless and his colleagues introduce the concept of sustainable feedback, which is defined as "dialogic processes and activities which can support and inform the student on the current task, whilst also developing the ability to self-regulate performance on future tasks" [48]. The core of sustainable feedback is its ability to let learners improve their work independently from the tutor, i.e., the ability to enable self-regulated learning. In particular, it was found that technology-assisted dialogue aimed at promoting learner autonomy and self-reflection is one of the key methods to promote sustainable feedback. Sustainable feedback can be viewed as an explicit example of how ICT can be effectively introduced to improve learning outcome, which is an important aspect of SDG 4. Apart from learning motivation, Hannafin summarised the ways the interactive learning environment can support self-regulation skills [49]. He stated that functions such as menu and navigational control may support the use of metacognitive skills, such as planning the learning activities. Embedded questions asking for an answer from the learner may support memorization of previous knowledge, hence enhancing the use of rehearsal skills. The interactive features that prompt the seeking of supplementary materials and self-evaluation by using different types of questions can scaffold learner's metacognitive skills, elaboration, and organization skills [50].

The design and production of interactive materials for Mongolian primary school teacher training are carried out by carefully aligning the principles discussed in this section to ensure an effective learning experience. The detailed discussion is laid out in the following methodology section. 


\section{Methodology}

This section consists of six sub-sections. First, it explains how interactive materials were developed and used in teacher training in primary schools. Second, questionnaire development using the Motivated Strategies for Learning Outcome (MSQL) survey as well as learning satisfaction and training effectiveness survey, and data collection are described. Next two sections describe preparatory analysis of the data collected, using factor analysis and $t$-test. Then, the $t$-test result is used to develop the research question and hypotheses. In the last section, moderation analysis is explained as a data analysis method to answer the research question.

\subsection{Implementation of Training with Interactive Materials}

\subsubsection{Development of Interactive Teacher Training Materials}

The production of interactive teacher training materials took place using Xerte which was developed by University of Nottingham, UK [49]. Xerte is an open source authoring tool that allows users to produce interactive learning content which can be utilised either online or offline in any computer browser. The interactive teacher training materials were co-developed with the professional team representing the Mongolian National University of Education, Institute of Finance and Economy, and the Bayankhongor Education and Culture Department in three primary school subjects: Man and Environment, Man and Society and Art and Technology. The sources of information in developing interactive materials are teacher training guidelines and teacher training videos for primary school teachers developed between 2013 and 2016. The materials for each subject incorporate various interactive features such as using multiple choice questions, a set of quizzes, filling in the missing word, ordering sequences, matching pairs, free answer, as well as drag-and-drop labelling. Multiple choice questions are questions that prompt learners to choose correct options from the list. A set of quizzes includes multiple choice questions as well as true and false questions. Ordering sequences ask learners to put statements in the correct sequence. Matching pairs request the learner to match statements with another half of the statement. Free answer presents questions that are of an open-ended nature for learners to write down the answers, providing a reference answer when requested. Last, drag-and-drop labelling allows learners to place a tag on specific parts of the picture to match its meaning. Multimedia content such as picture scans from teacher training guidelines are integrated with the above listed interactive features. All interactive learning content features immediate feedback upon submitting the answer through the interactive learning materials. As a result, seventy-nine interactive learning tools were produced for three subjects in 2016. You may refer to the interactive learning materials developed in this study on Xerte community website at https://goo.gl/7PUqB9.

\subsubsection{Teacher Training with Interactive Materials}

Public primary school teachers in Bayankhongor Province, located in the Gobi region of Mongolia participated the in-service teacher training using interactive teacher training materials, a teacher training guideline and teacher training videos. The teacher training guideline is a textbook with subject-wise explanations on pedagogies that align with new education standards, which emphasizes a student-centred approach. Teacher training videos are produced by teachers themselves, which explain the pedagogies that reflect local contextual features, such as local scenery and locally available teaching resources.

This study applies a two-group experimental design where two groups of teachers were formulated to receive teacher training. The experimental group (teachers with interactive materials) refers to teachers who conduct self-development using interactive teacher training materials, the teacher training guideline and teacher training videos. The control group (teachers without interactive materials) refers to teachers who conduct self-development using the teacher training guideline and teacher training videos. There are 15 schools with 151 teachers in the experimental group, and 14 schools with 134 teachers in the control group. These two groups are composed of schools with 
comparable characteristics in terms of the different sizes of schools, numbers of schools and teachers, similar school performances, and geographical locations. The intervention using interactive teacher training materials for teacher training took place in April, 2016 for teachers in the experimental group.

\subsection{Data Collection}

Development of Survey Methodology

This study applied three survey instruments to measure SRL processes and learning outcomes. The Motivated Strategies for Learning Outcome Questionnaire (MSLQ) was localised to measure learning motivation and learning strategies for teachers receiving in-service teacher training [50]. This questionnaire was selected due to its proven reliability and validity across multiple targets of study populations and application in different regions [51-54]. A learning satisfaction survey and training effectiveness survey were selected to measure learning outcome $[55,56]$. The former measures learner's satisfaction with learning content in the distance learning context. The training effectiveness survey focuses on the learner's intention to apply knowledge and post-training self-efficacy. The final instrument consists of 17 items measuring learning motivation, 36 items measuring learning strategies, and 13 items measuring learning outcomes. All survey items are coded in 7-point Likert scale. A 7-point Likert scale was adopted in the questionnaire as having more point scales reduces problems of normality issues and increases sensitivity [57]. Further, a 5-point Likert scale could cause information loss, and the 7-point Likert scale is a preferred scale without imposing cognitive overload load on the respondents [58]. A dichotomous variable "usage of interactive material" is used to represent teachers using interactive materials (value $=1$ ) and teachers who do not use interactive material (value $=0$ ).

Data were collected in October, 2016 after teachers were engaged in self-development using teacher training materials for six months. The data collection was made possible in coordination with the local government and schools. Out of 285 survey questionnaires distributed, 257 were returned, yielding a $90.2 \%$ return rate. Through data cleaning, such as excluding samples with high missing rates, 248 samples were considered valid for further analysis.

\subsection{Preparatory Analysis of the Data: Exploratory Factor Analysis}

Exploratory factor analysis was applied to the data collected on self-regulated learning processes and learning outcome for two groups of teachers using IBM SPSS 23 [59]. Exploratory factor analysis is an important process to ensure convergent and discriminant validity of the dataset, and helps to avoid highly correlated items that may influence the validity of further analysis [60]. Varimax rotation was applied in the exploratory factor analysis to increase interpretability. Cronbach's Alpha was evaluated to find the internal reliability of theoretical components as well as latent variables derived from exploratory factor analysis [61].

For the first step, Cronbach's Alpha was evaluated for the theoretical components in self-regulated learning processes and learning outcome. As a result, several components are excluded from further analysis due to their low internal consistency. Specifically, control of learning beliefs $(\alpha=0.571)$, rehearsal skills $(\alpha=0.661)$, time and study environment management $(\alpha=0.578)$, peer learning $(\alpha=0.627)$, and help seeking $(\alpha=0.580)$.

Exploratory factor analysis was undertaken on items of theoretically reliable components. The analysis discovered six latent variables representing the following self-regulated learning processes and learning outcome (see Appendix A). Table 1 summarizes the identified factors with a descriptive label assigned to each factor. 
Table 1. List of factors with their rotated sums of squared loading, and reliability.

\begin{tabular}{lcccccc}
\hline & Factor & Total & $\begin{array}{c}\text { \% of } \\
\text { Variance }\end{array}$ & $\begin{array}{c}\text { Cumulative } \\
\text { Variance }\end{array}$ & $\begin{array}{c}\text { Number of } \\
\text { Items }\end{array}$ & $\begin{array}{c}\text { Cronbach's } \\
\text { Alpha }\end{array}$ \\
\hline 1 & $\begin{array}{c}\text { Internal motivation } \\
\text { Learning satisfaction and intention }\end{array}$ & 5.493 & 13.398 & 13.398 & 7 & 0.876 \\
2 & 4.887 & 11.919 & 25.317 & 5 & 0.907 \\
3 & to apply contents & & & & \\
4 & Cranning and organizing skills & 4.721 & 11.514 & 36.831 & 5 & 0.890 \\
5 & & 3.916 & 9.551 & 46.382 & 3 & 0.810 \\
6 & Motivation for better assessment & 1.949 & 6.461 & 52.843 & 1 & N/A \\
7 & Effort regulation & 1.802 & 4.846 & 57.689 & 2 & 0.700 \\
8 & & 1.375 & 3.353 & 62.085 & 2 & 0.698 \\
\hline
\end{tabular}

Six latent variables were created by summating and averaging the constructing items. Five factors identified that correspond with SRL processes. There are two factors that correspond to the motivational processes of SRL: internal motivation and motivation for better assessment. Internal motivation relates to the extent to which the learner feels interested in the teacher training, and the learner's perceived efficacy and value in studying for teacher training. Motivation for better assessment refers to teachers' perception about the value of doing well in teacher assessment. Three factors correspond with the learning strategies of SRL: planning and organizing skills, critical and positive thinking skills, and effort regulation. Planning and organizing skills are related to teachers' ability to plan and organize the learning materials, such as applying strategies to identify the important concepts to guide their study. Critical and positive thinking skills reflect the teachers' critical thinking skills in understanding statements in the teacher training materials and their ability to integrate existing knowledge with new knowledge. Effort regulation explains to what extent teachers are willing to cope with teacher training materials that are not attractive to them. There is one factor regarding learning outcome: learning satisfaction and intention to apply the learning content (also referred to as learning satisfaction). This factor is a composite measure for learning outcomes, specifically measuring learner's satisfaction with the learning contents and their intention to apply the knowledge in teaching practices.

\subsection{T-Test Analysis}

An independent samples $t$-test was used to determine if there were significant differences between the experimental group and the control group in terms of self-regulation processes and learning outcomes. Two significant differences were found.

First, as the results show in Table 2, among five self-regulated learning processes tested, teachers in the experimental group are more highly motivated to achieve better assessment (Mean $=5.27$, $\mathrm{SD}=1.163$ ) than teachers in the control group (Mean $=4.76, \mathrm{SD}=1.531$ ). This result agrees with the literature which found that an e-learning environment with self-assessment and timely and relevant feedback can enhance learning motivation because participants believe they will be better assessed [62]. Interviews with local primary school teachers in Mongolia also confirmed this finding. Teachers feel that conducting self-evaluation using interactive materials can help them with the areas of weakness in understanding the training content, and hence to do better in their assessment as a teacher.

Second, for learning outcomes, teachers in the experimental group have higher learning satisfaction and intention to apply the learning content (Mean $=6.01, \mathrm{SD}=0.922$ ) than teachers in the control group (Mean $=5.76, \mathrm{SD}=0.986$ ). This finding agrees with previous research which found that quality multimedia interactive learning materials can enhance learning satisfaction in college level education [63]. In the Mongolian context, focus group discussion with teachers revealed three specific features of the interactive materials that promoted teachers' satisfaction. First, as mentioned earlier, learning with the interactive materials helps learners to identify what they know and they do not know. Second, interactive materials help learners to keep their learning on track through quizzes, because the interactive training programme informs the users of their level of understanding through 
correction rates on the quizzes. Third, learners using interactive materials feel they can better focus on important learning content as the programme highlights the core theories and important concepts.

Table 2. T-test results of five SRL processes and learning satisfaction and intention to apply learning contents.

\begin{tabular}{|c|c|c|c|c|c|c|c|c|c|}
\hline \multirow{3}{*}{$\begin{array}{l}\text { Self-Regulated Learning Processes } \\
\text { and Learning Outcome }\end{array}$} & \multicolumn{6}{|c|}{ Teacher Training Group } & \multirow[b]{3}{*}{$\mathbf{t}$} & \multirow[b]{3}{*}{ df } & \multirow[b]{3}{*}{$p$} \\
\hline & \multicolumn{3}{|c|}{ Experimental Group } & \multicolumn{3}{|c|}{ Control Group } & & & \\
\hline & Mean & SD & $\mathbf{n}$ & Mean & SD & $\mathbf{n}$ & & & \\
\hline Internal motivation & 5.77 & 0.843 & 127 & 5.58 & 0.983 & 109 & 1.593 & 214 & 0.113 \\
\hline Planning and organizing skills & 5.70 & 0.968 & 129 & 5.57 & 1.126 & 112 & 0.926 & 220 & 0.355 \\
\hline Critical and positive thinking skills & 5.50 & 1.062 & 131 & 5.43 & 1.053 & 115 & 1.118 & 228 & 0.236 \\
\hline Motivation for better assessment & 5.27 & 1.163 & 129 & 4.76 & 1.531 & 116 & 2.921 & 243 & $0.004^{* *}$ \\
\hline Effort regulation & 5.22 & 1.469 & 131 & 5.11 & 1.248 & 116 & 0.632 & 244 & 0.528 \\
\hline $\begin{array}{l}\text { Learning satisfaction and intention to } \\
\text { apply learning contents }\end{array}$ & 6.01 & 0.922 & 131 & 5.76 & 0.986 & 114 & 1.995 & 233 & $0.047^{*}$ \\
\hline
\end{tabular}

Note. ${ }^{*} p<0.05,{ }^{* *} p<0.01,{ }^{* * *} p<0.001$.

\subsection{Research Question and Hypothesis}

\subsubsection{Research Question}

The research objective is to investigate how interactive learning materials can support self-regulated learning processes and learning satisfaction. Given that the $t$-test results revealed the significant differences between experimental and control group teachers in their motivation for better assessment and learning satisfaction, the research question was formulated as follows: does the use of interactive materials affect the relationship between motivation for better assessment and learning satisfaction and intention to apply learning contents?

\subsubsection{Hypothesis}

This section lays out five important hypotheses. First, reflecting the significant difference between the experimental group and the control group in motivation for better assessment and learning satisfaction, Hypothesis 1 is created as follows.

Hypothesis 1 (H1). The influence of teachers' motivation for better assessment on learning satisfaction and intention to apply learning contents is stronger for teachers who utilise interactive materials [64].

In this study, it is also important to examine the effect of interactive materials on the relationship between four other processes of self-regulated learning and learning satisfaction as a significant difference was found in learning satisfaction between two groups. This result cannot deny the possible influence of other self-regulated learning process factors, namely, internal motivation, planning and organizing skills, critical and positive thinking skills, and effort regulation, on learning satisfaction. Therefore, the following four hypotheses were tested.

Hypothesis 2 (H2). The influence of teachers' internal motivation on learning satisfaction and intention to apply learning contents is stronger for teachers who utilise interactive materials [20].

Hypothesis 3 (H3). The influence of teachers' critical and positive thinking skills on learning satisfaction and intention to apply learning contents is stronger for teachers who utilise interactive materials [65].

Hypothesis 4 (H4). The influence of teachers' planning and organizing skills on learning satisfaction and intention to apply learning contents is stronger for teachers who utilise interactive materials [66]. 
Hypothesis 5 (H5). The influence of teachers' effort regulation on learning satisfaction and intention to apply learning contents is stronger for teachers who utilise interactive materials [67].

\subsection{Data Analysis Method}

\subsubsection{Moderation Analysis}

Moderated multiple regression analysis was utilised for answering the research question. An interaction effect is said to exist when the effect of the independent variable on the dependent variable differs depending on the value of a third variable, called the moderator variable [68]. A moderation analysis is to test the hypothesis explaining the effect of an independent variable on dependent variable that is influenced by the value of another independent variable, also called a moderator variable [69]. This effect is named the moderator effect. The method to determine if a moderator effect exists uses an interaction term in the multiple regression analysis. An interaction term is created by multiplying the independent and moderator variable. This is then added to the regression model to predict the dependent variable.

This study, therefore, employs moderation analysis focusing on examining the moderation effect of interactive materials on the relationship between the self-regulation process and learning satisfaction. In this context, the following moderated regression models were created to test the hypotheses mentioned earlier. Specifically, five moderated multiple regression models in correspondence with the five hypotheses are created as shown below.

Moderated regression model 1:

$$
\text { Satisfaction }=b_{0}+b_{1} \text { Motiv }+b_{2} \text { Interact }+b_{3} \text { Motiv } \times \text { Interact }+b_{4} \text { Intr }+b_{5} \text { Crit }+b_{6} \text { Planorg }+b_{7} \text { Eff }
$$

Moderated regression model 2:

$$
\text { Satisfaction }=b_{0}+b_{1} \text { Intr }+b_{2} \text { Interact }+b_{3} \text { Intr } \times \text { Interact }+b_{4} \text { Motiv }+b_{5} \text { Crit }+b_{6} \text { Planorg }+b_{7} \text { Eff }
$$

Moderated regression model 3:

$$
\text { Satisfaction }=b_{0}+b_{1} \text { Crit }+b_{2} \text { Interact }+b_{3} \text { Crit } \times \text { Interact }+b_{4} \text { Intr }+b_{5} \text { Motiv }+b_{6} \text { Planorg }+b_{7} \text { Eff }
$$

Moderated regression model 4:

$$
\text { Satisfaction }=b_{0}+b_{1} \text { Planorg }+b_{2} \text { Interact }+b_{3} \text { Planorg } \times \text { Interact }+b_{4} \text { Intr }+b_{5} \text { Motiv }+b_{6} \text { Crit }+b_{7} \text { Eff }
$$

Moderated regression model 5:

$$
\text { Satisfaction }=b_{0}+b_{1} \text { Eff }+b_{2} \text { Interact }+b_{3} \text { Eff } \times \text { Interact }+b_{4} \text { Intr }+b_{5} \text { Motiv }+b_{6} \text { Crit }+b_{7} \text { Planorg }
$$

where: Satisfaction-learning satisfaction and intention to apply learning contents; Interact-use of interactive material; Motiv—-motivation for better assessment; Intr-internal motivation; Crit-critical and positive thinking skills; Planorg—planning and organizing skills; Eff—effort regulation.

\subsubsection{Qualitative Analysis}

The researchers organized the qualitative data collection in Mongolia in September, 2017. The results of the quantitative analysis were presented to the group of 60 teachers in primary schools. Semi-structured focus group discussions and interviews were organized involving teachers and educational administrators. The results of the discussions were used to supplement and interpret the quantitative data analysis results. 


\section{Results}

Out of five models tested (Appendix B), two moderated regression models showed statistically the significant moderation effect of interactive materials.

First, the result of moderated regression model 1 shows that the use of interactive material moderates the influence of motivation for better assessment on learning satisfaction and intention to apply the learning content. Figure 1 is a graphical depiction of this result. The F-test shows the significance of the model, where $\mathrm{F}(7,248)=41.074$, significant at $p<0.0001$ level. The model explains $53.1 \%$ of the variance in learning satisfaction and intention to apply learning contents $\left(\mathrm{R}^{2}=0.531\right)$.

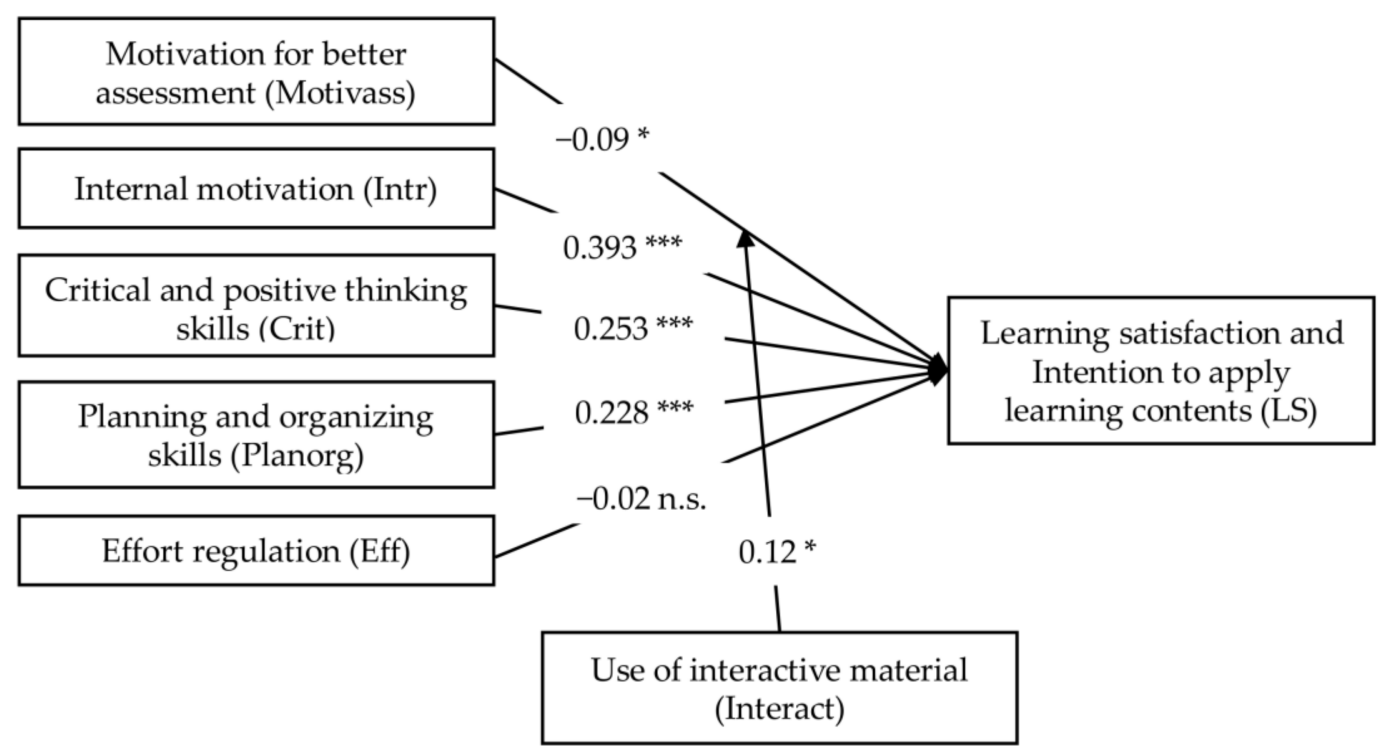

Figure 1. Result of moderated regression model 1 (Note: n.s. not significant, ${ }^{*} p<0.05,{ }^{* * *} p<0.005$, **** $p<0.0005)$.

The results of the moderated regression model 1 is described as follows:

Satisfaction $=1.458-0.09 \mathrm{Motiv}+0.12 \mathrm{Motiv} \times$ Interact $+0.393 \mathrm{Intr}+0.253 \mathrm{Crit}+0.228$ Planorg

It demonstrates that for teachers in the experimental group, a unit increase in motivation for better assessment positively influences learning satisfaction and intention to apply learning contents by 0.03 units, controlling the effect of internal motivation, critical and positive thinking skills, and planning and organizing skills. Meanwhile, for teachers in the control group, a unit increase in motivation for better assessment negatively influences learning satisfaction and the intention to apply learning contents by 0.09 units, controlling the other independent variables. As a result, Hypothesis 1 is supported, which states that the influence of teachers' motivation for better assessment on learning satisfaction and intention to apply learning contents is stronger for teachers who utilise interactive materials.

There are other three non-moderated independent variables showing significant influence on learning satisfaction. According to the interpretation of moderation models with multiple independent variables by Hayes, the major focus of a moderation model is to examine the moderation effect while controlling other independent variables in the model [70]. Therefore, the interpretation of the regression coefficients of the non-moderated independent variables is not important, as their function is to serve as essential elements in the accurate estimation of model coefficients.

Second, the result of moderated regression model 2 shows that the use of interactive material moderates the influence of internal motivation on learning satisfaction and intention to apply learning contents. Figure 2 is a graphical depiction of this result. The F-test shows the significance of the model, 
where $\mathrm{F}(7,248)=41.371$, significant at $p<0.0001$ level. Model 2 explains $53.3 \%$ of the variance in learning satisfaction and intention to apply learning contents $\left(R^{2}=0.533\right)$.

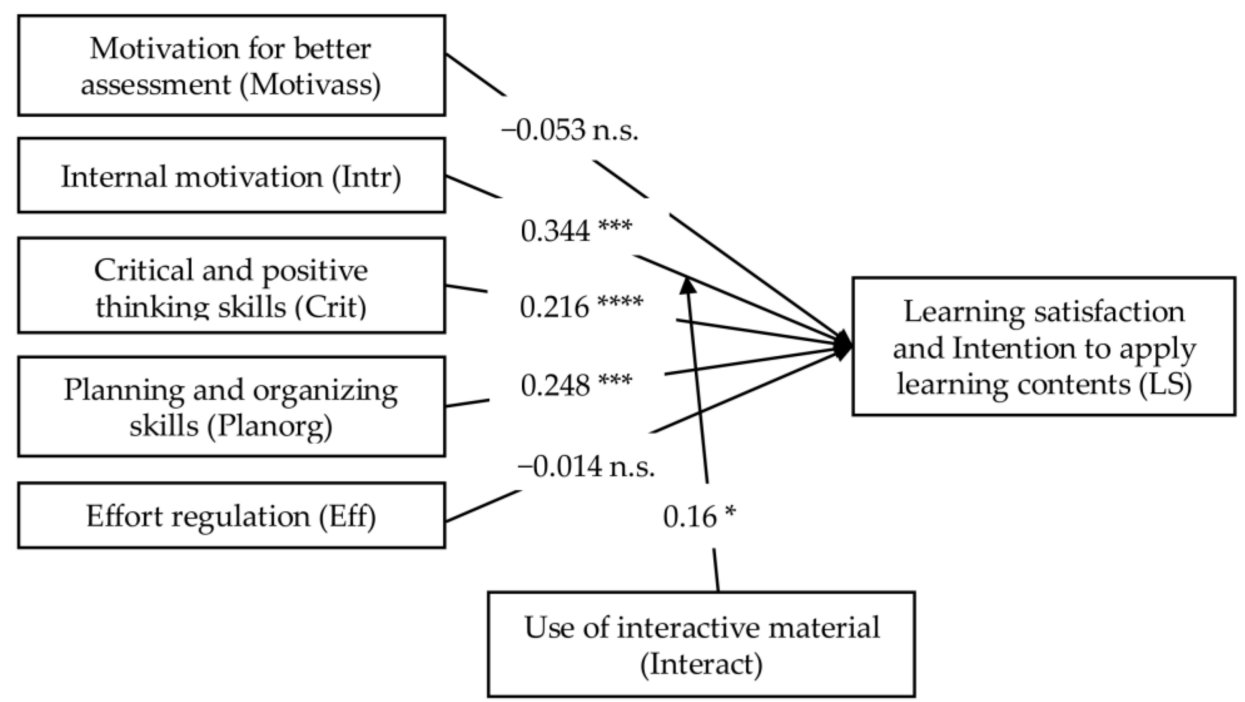

Figure 2. Result of moderated regression model 2 (Note: n.s. not significant, ${ }^{*} p<0.05,{ }^{* * *} p<0.005$, **** $p<0.0005)$.

The result of moderated regression model 2 is described as follows:

$$
\text { Satisfaction }=1.616+0.344 \text { Intr }+0.16 \text { Intr } \times \text { Interact }+0.248 \text { Planorg }+0.216 \text { Crit }
$$

It demonstrates that for teachers in the experimental group, a unit increase in internal motivation positively influences learning satisfaction and intention to apply learning contents by 0.504 units, controlling the effect of planning and organizing skills, and critical and positive thinking skills. Meanwhile, for teachers in the control group, a unit increase in internal motivation positively influences learning satisfaction and intention to apply learning contents by 0.344 units, controlling the effect of other independent variables. As a result, Hypothesis 2 is supported, which states that the influence of teachers' internal motivation on learning satisfaction and intention to apply learning contents is stronger for teachers who utilise interactive materials.

There are other two non-moderated independent variables showing significant influence on learning satisfaction, but they do not need to be specifically interpreted as the main focus is on the moderated independent variable, and their function is to serve as important elements in the model estimation.

\section{Discussion}

This section interprets the results of the data analysis in relation to the current discussion in the literature.

5.1. Motivation for Better Assessment of Teachers Who Use Interactive Materials Positively Influences Learning Satisfaction and Intention to Apply Learning Contents

The study found that the motivation for better assessment of teachers in the experimental group positively influenced learning satisfaction and intention to apply learning content while that of teachers in the control group negatively influenced learning satisfaction. This finding supports the research of Cheng which indicated that extrinsic motivation of learners using interactive e-learning materials positively influences their learning satisfaction [64]. It explains how interactive features promote learners' ability to control the timing and display of the contents. Further, it functions to 
support real-time reciprocal communication, which helps learners to conduct self-assessment via instant feedback. This helps teachers build confidence in their knowledge, resulting in learning satisfaction. The analysis of the qualitative data collected from teachers in Mongolia indicated that interactive materials have two key characteristics that relate to the positive relationship between motivation for better assessment and learning satisfaction. First, interactive materials allow teachers to assess themselves without stress from peers because they can learn at their own personal pace. Second, spontaneous responses from the interactive material helps teachers to understand the learning progress. The challenging features of answering quizzes motivate them to get better scores. Thus, these personalised and timely features of interactive materials were found to induce teachers' motivation affecting learning satisfaction.

\subsection{Internal Motivation of Teachers Who Use Interactive Materials Results in Higher Learning Satisfaction and Intention to Apply Learning Contents}

The study found that the internal motivation of teachers in the experimental group resulted in a higher level of learning satisfaction and intention to apply learning contents. Consistent with a previous study [20], this result supports the argument that learners' interest and curiosity enhance their satisfaction when the interactive materials support self-learning in a personalised environment. The analysis of the qualitative data collected from focus group discussions with local teachers shows that their learning satisfaction was higher when using interactive materials for two reasons. First, the interactive materials allow them to grasp the key concept more easily, helping to improve their professional competence and result in learning satisfaction. Second, time saving is another aspect that relates teachers' internal motivation to learning satisfaction. Specifically, motivated teachers utilise interactive materials to regularly assess their levels of understanding using the quiz and feedback features. In comparison, teachers feel that learning from written materials and videos lack an assessment aspect and a sense of self-reflection. Further, questions about specific pedagogies help teachers to reflect on their own teaching environment, resulting in them promoting student-centred lessons.

\section{Limitations and Future Research}

There are two limitations in the methodology of this study. The first issue is related to the level of difficulty in answering the survey questions. Specifically, some respondents reported difficulty in answering the questions due to the randomization of the question order in the survey. Although this does not affect the validity of the instrument as demonstrated in the data analysis, having the questions with grouped items may help teachers in answering in an easier manner. Second, it should be noted that the data sample is from one province, which may not generalize to the entire cohort of primary school teachers in Mongolia. Specifically, the study focused on schools in the rural part of Mongolia where contextual features are considered to be different from urban schools located in the capital city, for example. As the sample size of this study represents $6 \%$ of the rural teacher population [71], and reflects a relatively homogeneous characteristic of the ethnic background of the Mongolian population, the study result can be considered a good illustration of rural teachers in Mongolia. It is recommended that subsequent studies focus on the urban teacher population to complement the findings of this study, to further understand the effect of interactive materials on self-regulated learning for teachers in Mongolia.

\section{Conclusions}

Based on Pintrich's self-regulated learning theory, this research explored the influence of interactive learning materials on teachers' self-regulated learning processes and learning satisfaction in Mongolia. The preliminary data analysis using responses from 285 teachers identified five self-regulated learning processes, namely, internal motivation, planning and organizing skills, critical and positive thinking skills, motivation for better assessment, and effort regulation. The moderation 
analysis found the use of interactive materials has a positive influence on the relationship between motivation for better assessment and learning satisfaction. Furthermore, it was found that interactive materials have a positive influence on the relationship between internal motivation and learning satisfaction. These are the major contributions to the current discussion on the effect of interactive learning materials on self-regulated learning processes and learning satisfaction, particularly in the context of teacher development.

This study offers evidence for the positive influence of interactive learning materials on learners self-regulated learning processes and learning outcomes. These findings in rural Mongolia are significant given that self-development is crucial for teachers' professional development. Further, this study illustrates that motivational processes have a stronger influence on learning satisfaction and intention to apply learning contents when interactive learning materials are utilised for teacher training. Motivated teachers who constantly improve their professional competency through self-development activities are vital in improving the quality of education. Therefore, these findings serve as evidence of the effectiveness of introducing interactive materials as part of teachers' sustainable professional development, which is emphasized in sustainable development goals. As teachers' interest in using interactive materials for self-development was found to be high, it is recommended that interactive materials be applied in school-based training to further improve the quality of teachers.

Acknowledgments: The authors greatly appreciate the close collaboration with the Ministry of Education, Culture, Science and Sports of Mongolia, Mongolian National University of Education, Mongolian University of Finance and Economics, Bayankhongor Education and Culture Department and primary school teachers in Bayankhongor province.

Author Contributions: Shengru Li designed, implemented and evaluated the interactive materials for teacher training in Mongolia. The entirety of the research was conducted under the supervision of Shinobu Yamaguchi and Jun-ichi Takada.

Conflicts of Interest: The authors declare no conflict of interest.

\section{Appendix A}

Table A1. Rotated Component Matrix (Note: loadings greater than 0.6 are highlighted in red).

\begin{tabular}{|c|c|c|c|c|c|c|c|c|}
\hline & \multicolumn{8}{|c|}{ Component } \\
\hline & 1 & 2 & 3 & 4 & 5 & 6 & 7 & 8 \\
\hline Slfef 3: I expect to do well in this teacher training. & 0.702 & 0.142 & 0.160 & 0.310 & 0.025 & -0.067 & 0.135 & 0.192 \\
\hline $\begin{array}{l}\text { Slfef 1: I'm confident I can understand the basic concepts taught in } \\
\text { teacher training. }\end{array}$ & 0.626 & 0.097 & 0.004 & 0.346 & 0.131 & 0.248 & 0.000 & -0.116 \\
\hline $\begin{array}{l}\text { Tskv 3: I am very interested in the content area of the teacher } \\
\text { training materials. }\end{array}$ & 0.615 & 0.101 & 0.221 & 0.312 & -0.103 & 0.215 & 0.106 & 0.267 \\
\hline $\begin{array}{l}\text { Intr 2: In teacher training, I prefer the materials that arouses my curiosity, } \\
\text { even if it is difficult to learn. }\end{array}$ & 0.610 & 0.073 & 0.295 & 0.201 & 0.123 & 0.131 & 0.176 & 0.343 \\
\hline $\begin{array}{l}\text { Intr 1: In teacher training, I prefer the materials that really challenge me so } \\
\text { I can learn new things. }\end{array}$ & 0.607 & 0.368 & 0.207 & -0.011 & 0.198 & 0.076 & -0.046 & -0.058 \\
\hline $\begin{array}{l}\text { Slfef } 4 \text { : I'm certain I can master the skills being taught in this } \\
\text { teacher training. }\end{array}$ & 0.529 & 0.362 & 0.134 & 0.107 & 0.374 & 0.190 & -0.017 & -0.068 \\
\hline $\begin{array}{l}\text { Tskv 1: I think I will be able to use what I learn in teacher training in } \\
\text { teaching activities. }\end{array}$ & 0.498 & 0.371 & 0.075 & 0.077 & 0.225 & 0.111 & -0.037 & 0.144 \\
\hline
\end{tabular}


Table A1. Cont.

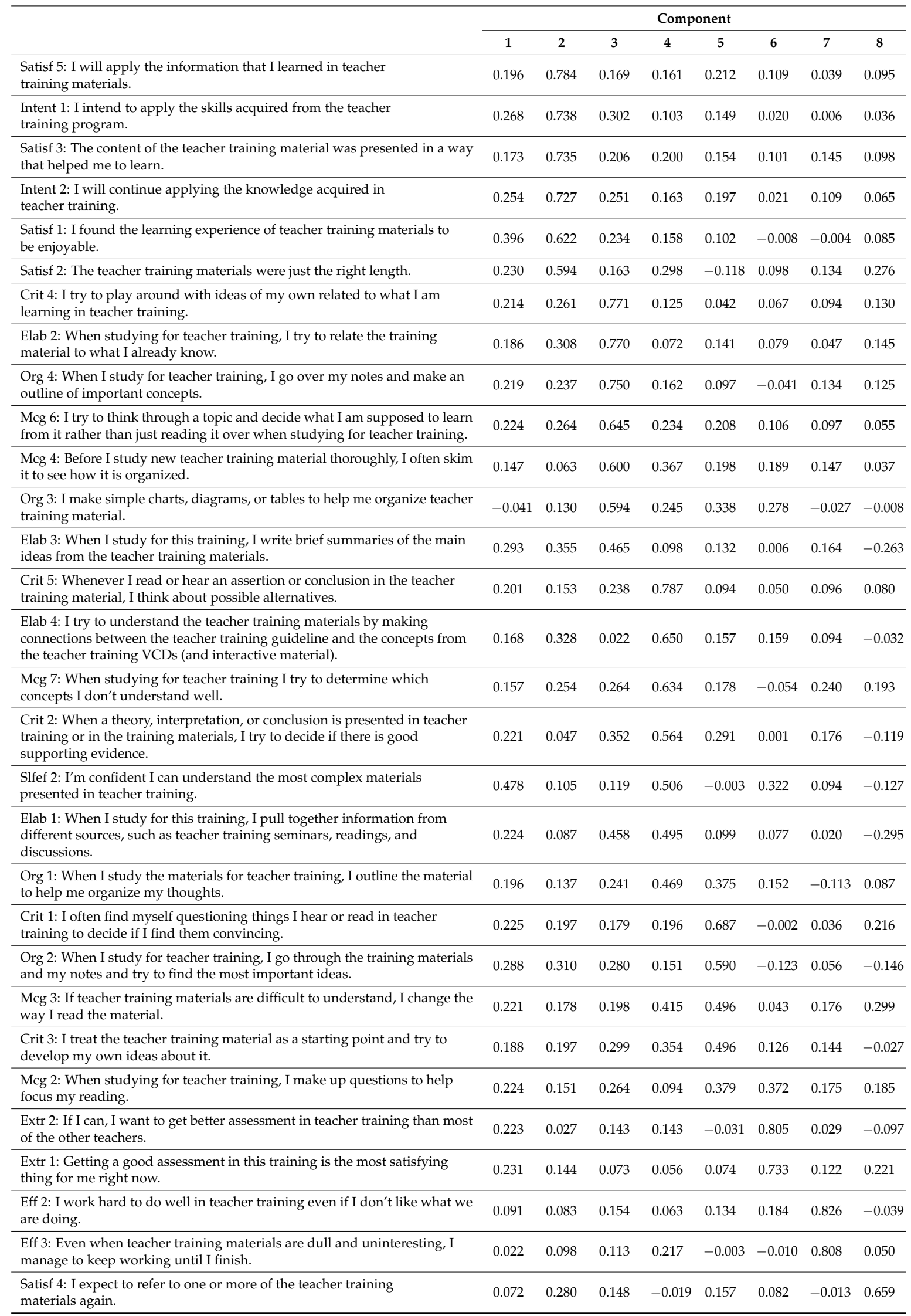

Extraction Method: Principal Component Analysis. Rotation Method: Varimax with Kaiser Normalization. Rotation converged in 13 iterations. 


\section{Appendix B}

Table A2. Moderated multiple linear regression results.

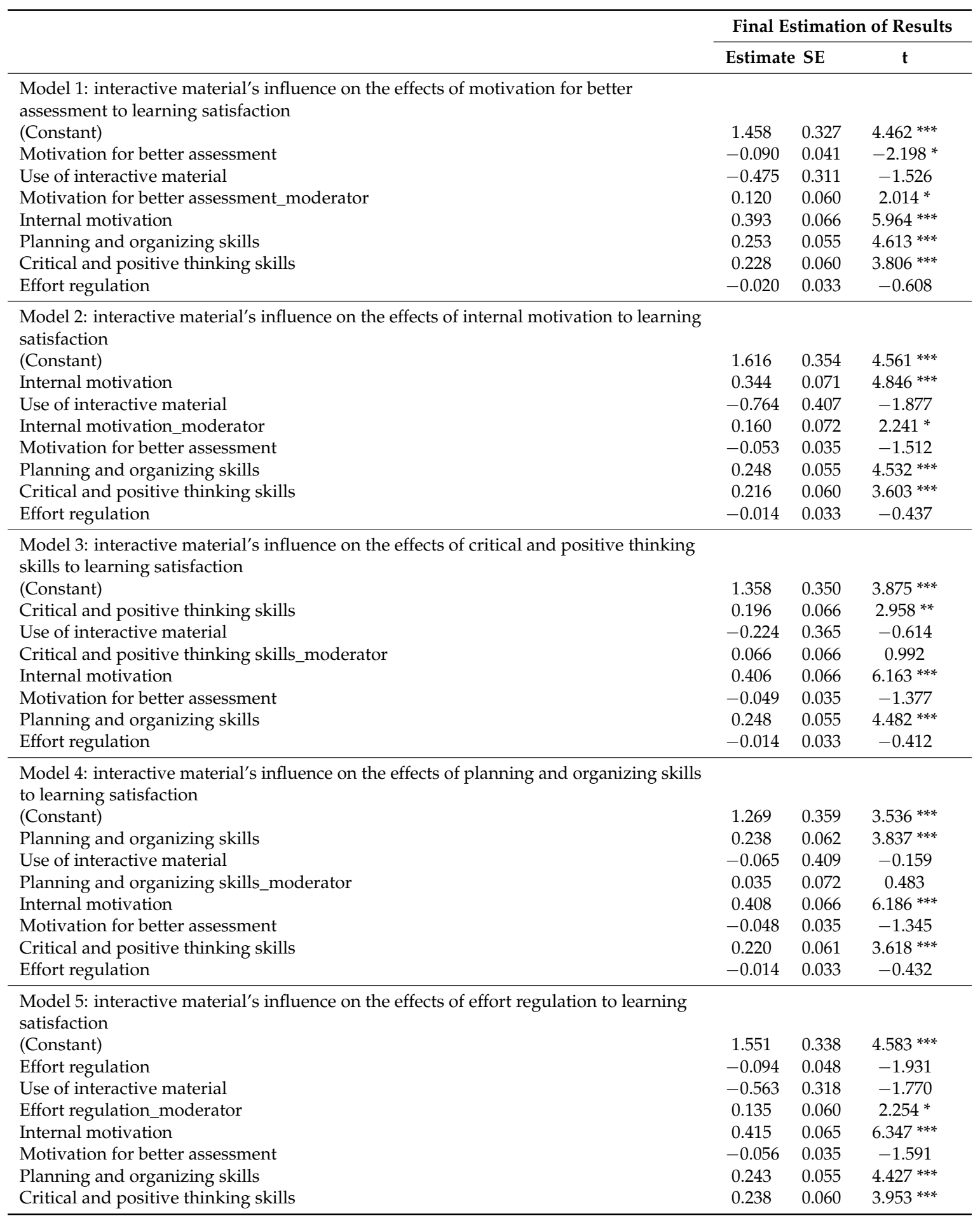




\section{References}

1. United Nations. The Future We Want; United Nations: Rio de Janeiro, Brazil, 2012.

2. United Nations Sustainable Development Goal 4. Available online: https://sustainabledevelopment.un. org/sdg4 (accessed on 26 March 2018).

3. UNESCO. Positioning ICT in Education to Achieve the Education 2030 Agenda in Asia and the Pacific: Recommendations for a Regional Strategy; UNESCO: Paris, France, 2018.

4. UNDP Formulating the Post-2015 Development Agenda. Available online: http:/ /www.un-mongolia.mn/ new/wp-content/uploads/2014/12/Post-2015_Eng.pdf (accessed on 26 July 2015).

5. Government of Mongolia Master Plan to Develop Education of Mongolia in 2006-2015. Available online: http:/ / planipolis.iiep.unesco.org/upload/Mongolia/MongoliaEducationMasterPlan2006-2015.pdf (accessed on 5 April 2018).

6. Information Communications Technology and Post Authority of Mongolia. The White Paper on ICT Development of Mongolia; Information Communications Technology and Post Authority of Mongolia: Ulaanbaatar, Mongolia, 2011.

7. Ministry of Education Culture and Science. Information and Communication Technology In Education Policy (2012-2016); Ministry of Education Culture and Science: Ulaanbaatar, Mongolia, 2012.

8. Ministry of Education Culture Science and Sports. Action Plan of the Information and Communication Technology In Education Policy (2012-2016); Ministry of Education Culture Science and Sports: Ulaanbaatar, Mongolia, 2018.

9. Ministry of Education Culture Science and Sports Web Portal for School. Available online: http:/ / econtent. edu.mn/content/library.html (accessed on 24 November 2017).

10. Tokyo Institute of Technology. Sustainable Use of ICT for Improving the Quality of Primary Education in Rural Mongolia; Tokyo Institute of Technology: Tokyo, Japan, 2012.

11. Pintrich, P.R. The Role of Goal Orientation in Self-Regulated Learning. Handb. Self-Regul. 2000, 451-502. [CrossRef]

12. Hwang, Y.S.; Vrongistinos, K. Elementary in-service teachers' self-regulated learning strategies related to their academic achievements. J. Instr. Psychol. 2002, 29, 147-154.

13. Liou, P.-Y.; Kuo, P.-J. Validation of an instrument to measure students' motivation and self-regulation towards technology learning. Res. Sci. Technol. Educ. 2014, 32, 79-96. [CrossRef]

14. Young, J.D. The effect of self-regulated learning strategies on performance in learner controlled computer-based instruction. Educ. Technol. Res. Dev. 1996, 44, 17-27. [CrossRef]

15. Zimmerman, B.J. Self-Regulated Learning and Academic Achievement: An Overview. Educ. Psychol. 1990, 25, 3-17. [CrossRef]

16. Pintrich, P.R.; De Groot, E.V. Motivational and Self-Regulated Learning Components of Classroom Academic Performance. J. Educ. Psychol. 1990, 82, 33-40. [CrossRef]

17. Boekaerts, M.; Pintrich, P.R.; Zeidner, M. Handbook of Self-Regulation; Academic Press: London, UK, 2000; ISBN 0121098907.

18. Zimmerman, B.J. Becoming a Self-Regulated Learner: An Overview. Theory Pract. 2002, 41, 64-70. [CrossRef]

19. Schraw, G.; Crippen, K.J.; Hartley, K. Promoting Self-Regulation in Science Education: Metacognition as Part of a Broader Perspective on Learning. Res. Sci. Educ. 2006, 36, 111-139. [CrossRef]

20. Carneiro, R.; Lefrere, P.; Steffens, K.; Underwood, J. Self-Regulated Learning in Technology Enhaced Learning Environments A European Perspective; Springer: Berlin, Germany, 2011; ISBN 9789460916526.

21. Fullan, M. The New Meaning of Educational Change; Teacher College Press: New York, NY, USA, 2007; ISBN 0415439566.

22. Borko, H. Professional Development and Teacher Learning: Mapping the Terrain. Educ. Res. 2004, 33, 3-15. [CrossRef]

23. Wesley, P.W.; Buysse, V. Communities of Practice: Expanding Professional Roles to Promote Reflection and Shared Inquiry. Top. Early Child. Spec. Educ. 2001, 21, 114-123. [CrossRef]

24. Rennie, L.J. Teacher Collaboration in Curriculum Change: The Implementation of Technology Education in the Primary School. Res. Sci. Educ. 2001, 31, 49-69. [CrossRef]

25. Butler, D.L.; Lauscher, H.N.; Jarvis-Selinger, S.; Beckingham, B. Collaboration and self-regulation in teachers' professional development. Teach. Teach. Educ. 2004, 20, 435-455. [CrossRef] 
26. Isikoglu, N.; Basturk, R.; Karaca, F. Assessing in-service teachers' instructional beliefs about student-centered education: A Turkish perspective. Teach. Teach. Educ. 2009, 25, 350-356. [CrossRef]

27. Perry, N.E.; Walton, C.; Calder, K. Teachers Developing Assessments of Early Literacy: A Community of Practice Project. Teach. Educ. Spec. Educ. 1999, 22, 218-233. [CrossRef]

28. Henry, S.K.; Scott, J.A.; Wells, J.; Skobel, B.; Jones, A.; Cross, S.; Butler, C.; Blackstone, T. Linking University and Teacher Communities: A “Think Tank" Model of Professional Development. Teach. Educ. Spec. Educ. 1999, 22, 251-268. [CrossRef]

29. UNESCO-IBE. World Data on Education-Mongolia, VII Ed. 2010/11; UNESCO-IBE: Geneva, Switzerland, 2011.

30. Mon-Educ Consulting LLC. Report of the Impact Survey of "Quality Improvement of Primary Education Teachers through Development of Training Materials Using ICT" Project Funded by JICA, Japan; Mon-Educ Consulting LLC: Ulaanbaatar, Mongolia, 2017.

31. Dettori, G.; Persico, D. Fostering Self-Regulated Learning through ICT; Information Science Reference; IGI Global: Hershey, PA, USA, 2011; ISBN 1616929030.

32. Eom, W.; Reiser, R. The Effects of Self-Regulation and Instructional Control on Performance and Motivation in Computer-based Instruction. Int. J. Instr. Media 2000, 27, 247-261.

33. Zimmerman, B.J.; Bandura, A.; Martinez-Pons, M. Self-Motivation for Academic Attainment: The Role of Self-Efficacy Beliefs and Personal Goal Setting. Am. Educ. Res. J. 1992, 29, 663-676. [CrossRef]

34. Littlejohn, A.; Hood, N.; Milligan, C.; Mustain, P. Learning in MOOCs: Motivations and self-regulated learning in MOOCs. Internet High. Educ. 2016, 29, 40-48. [CrossRef]

35. Eom, S.; Wen, H.; Ashill, N. The determinants of students' perceived learning outcomes and satisfaction in university online education: An empirical investigation. Decis. Sci. J. 2006, 4, 215-235. [CrossRef]

36. Pintrich, P. A Conceptual Framework for Assessing Motivation and Self-Regulated Learning in College Students. Educ. Psychol. Rev. 2004, 16, 385-407. [CrossRef]

37. Artino, A.R. Online military training using a social cognitive view of motivation and self-regulation to understand students' satisfaction, perceived learning, and choice. Q. Rev. Distance Educ. 2007, 8, 191-202.

38. Moore, M.G. Editorial: Three types of interaction. Am. J. Distance Educ. 1989, 3, 1-7. [CrossRef]

39. Hannafin, M.J. Interaction strategies and emerging instructional technologies. Can. J. Educ. Commun. 1989, 18, 167-179.

40. Schwier, R.; Misanchuk, E. Interactive Multimedia Instruction; Educational Technology: Englewood Cliffs, NJ, USA, 1993.

41. Sims, R. Interactivity: A forgotten art? Comput. Hum. Behav. 1997, 13, 157-180. [CrossRef]

42. Domagk, S.; Schwartz, R.N.; Plass, J.L. Interactivity in multimedia learning: An integrated model. Comput. Hum. Behav. 2010, 26, 1024-1033. [CrossRef]

43. Kennedy, G.E. Promoting Cognition in Multimedia Interactivity Research. J. Interact. Learn. Res. 2004, 15, 43-61.

44. Moreno, R.; Mayer, R.E. Role of Guidance, Reflection, and Interactivity in an Agent-Based Multimedia Game. J. Educ. Psychol. 2007, 97, 117-128. [CrossRef]

45. Lynch, R.; Dembo, M. The Relationship Between Self-Regulation and Online Learning in a Blended Learning Context. Int. Rev. Res. Open Distrib. Learn. 2004, 5. [CrossRef]

46. Keller, J.M.; Suzuki, K. Learner Motivation and E-Learning Design: A Multinationally Validated Process. J. Educ. Media 2004, 29, 229-239. [CrossRef]

47. Keller, J.M. First principles of motivation to learn and $\mathrm{e}^{3}$-learning. Distance Educ. 2008, 29, 175-185. [CrossRef]

48. Carless, D.; Salter, D.; Yang, M.; Lam, J. Developing sustainable feedback practices. Stud. High. Educ. 2011, 36, 395-407. [CrossRef]

49. Xerte Community What's Xerte? Available online: http://www.xerte.org.uk/index.php?option=com content\&view=article\&id=77\&Itemid=546\&lang=en (accessed on 7 September 2017).

50. Pintrich, P.; Smith, D.; Garcia, T.; McKeachie, W. A Manual for the Use of the Motivated Strategies for Learning Questionnaire (MSLQ). Available online: https:/ / files.eric.ed.gov/fulltext/ED338122.pdf (accessed on 5 April 2018).

51. Duncan, T.G.; McKeachie, W.J. The Making of the Motivated Strategies for Learning Questionnaire. Educ. Psychol. 2005, 40, 117-128. [CrossRef]

52. Kramarski, B.; Michalsky, T. Investigating preservice teachers' professional growth in self-regulated learning environments. J. Educ. Psychol. 2009, 101, 161-175. [CrossRef] 
53. Moos, D.C. Nonlinear technology: Changing the conception of extrinsic motivation? Comput. Educ. 2010, 55, 1640-1650. [CrossRef]

54. Kuo, Y.C.; Walker, A.E.; Schroder, K.E.E.; Belland, B.R. Interaction, Internet self-efficacy, and self-regulated learning as predictors of student satisfaction in online education courses. Internet High. Educ. 2014, 20, 35-50. [CrossRef]

55. Pintz, C.; Posey, L. Preparing students for graduate study: An eLearning approach. Nurse Educ. Today 2013, 33, 734-738. [CrossRef] [PubMed]

56. Zhao, X.; Namasivayam, K. Posttraining Self-Efficacy, Job Involvement, and Training Effectiveness in the Hospitality Industry. J. Hum. Resour. Hosp. Tour. 2009, 8, 137-152. [CrossRef]

57. Leung, S.-O. A Comparison of Psychometric Properties and Normality in 4-, 5-, 6- and 11-Point Likert Scales. J. Soc. Serv. Res. 2011, 37, 412-421. [CrossRef]

58. Finstad, K. Response Interpolation and Scale Sensitivity: Evidence Against 5-Point Scales. J. Usability Stud. 2010, 5, 104-110.

59. IBM IBM SPSS-IBM Analytics. Available online: https://www.ibm.com/analytics/us/en/technology/ spss / (accessed on 7 September 2017).

60. Hair, J.J.F.; Black, W.C.; Babin, B.J.; Anderson, R.E. Multivariate Data Analysis, 7th ed.; Prentice Hall: New York, NY, USA, 2009; ISBN 9780135153093.

61. Tavakol, M.; Dennick, R. Making sense of Cronbach's alpha. Int. J. Med. Educ. 2011, 2, 53. [CrossRef] [PubMed]

62. Law, K.M.Y.; Lee, V.C.S.; Yu, Y.T. Learning motivation in e-learning facilitated computer programming courses. Comput. Educ. 2010, 55, 218-228. [CrossRef]

63. Violante, M.G.; Vezzetti, E. Virtual interactive E-learning application: An evaluation of the student satisfaction. Comput. Appl. Eng. Educ. 2015, 23, 72-91. [CrossRef]

64. Cheng, Y.-M. Roles of interactivity and usage experience in e-learning acceptance: A longitudinal study. Int. J. Web Inf. Syst. 2014, 10, 2-23. [CrossRef]

65. Gharib, M.; Zolfaghari, M.; Mojtahedzadeh, R.; Mohammadi, A.; Gharib, A. Promotion of critical thinking in e-learning: A qualitative study on the experiences of instructors and students. Adv. Med. Educ. Pract. 2016, 7, 271-279. [CrossRef] [PubMed]

66. Delen, E.; Liew, J.; Willson, V. Effects of interactivity and instructional scaffolding on learning: Self-regulation in online video-based environments. Comput. Educ. 2014, 78, 312-320. [CrossRef]

67. Rakes, G.C.; Dunn, K.E. The impact of online graduate students' motivation and self-regulation on academic procrastination. J. Interact. Online Learn. 2010, 9, 78-93.

68. Jaccard, J.; Turrisi, R. Interaction Effects in Multiple Regression; Sage Publications: Thousand Oaks, CA, USA, 2003; ISBN 0761927425.

69. Aguinis, H. Regression Analysis for Categorical Moderators; Guilford Press: New York, NY, USA, 2003; ISBN 9781572309692.

70. Hayes, A. Introduction to Mediation, Moderation, and Conditional Process Analysis; Guilford: New York, NY, USA, 2013; pp. 3-4.

71. Ministry of Education Culture Science and Sports Statistics on Education Sector (2016-2017). Available online: http:/ / www.mecss.gov.mn/EBSsta2017 (accessed on 27 March 2018).

(C) 2018 by the authors. Licensee MDPI, Basel, Switzerland. This article is an open access article distributed under the terms and conditions of the Creative Commons Attribution (CC BY) license (http://creativecommons.org/licenses/by/4.0/). 